\title{
In vitro susceptibility testing of yeasts to nystatin - low minimum inhibitory concentrations suggest no indication of in vitro resistance of Candida albicans, Candida species or non-Candida yeast species to nystatin
}

\author{
Pietro Nenoff ${ }^{*}$, Constanze Krüger ${ }^{1}$, Claudia Neumeister ${ }^{2}$, Ulrich Schwantes ${ }^{2}$ and Daniela Koch ${ }^{1}$ \\ ${ }^{1}$ Laboratory for Medical Microbiology, Mölbiser Hauptstrasse 8, 04571 Rötha / OT Mölbis, Germany \\ ${ }^{2}$ Dr. R. Pfleger GmbH, 96045 Bamberg, Germany
}

\begin{abstract}
In total, 14 yeast strains originating from patients with dermatomycoses, and 7 control strains (isolates from strain collections and collaborative ring trials) were investigated regarding their in vitro susceptibility to the polyene antifungal agent nystatin. Testing was performed using a broth microdilution assay based on the standardized method of susceptibility testing of yeasts per EUCAST (The European Committee on Antimicrobial Susceptibility Testing). Minimum inhibitory concentrations (MIC) for nystatin were measured. The reading of the MIC values was performed by both visual examination, and spectrophotometric measuring after 24 and 48 hours' incubation time at $36^{\circ} \mathrm{C}$.

The visual read-out of growth inhibition revealed MICs for nystatin in a range from 3.7 to $7.4 \mathrm{IU} / \mathrm{mL}$ ( 0.625 to $1.25 \mu \mathrm{g} / \mathrm{mL}$ ) for all Candida species tested. One of the Candida (C.) albicans strains, and both strains of C. glabrata and C. tropicalis, showed low MIC values of $3.7 \mathrm{IU} / \mathrm{mL}(0.625 \mu \mathrm{g} / \mathrm{mL})$. Geotrichum candidum and Trichosporon mucoides were also inhibited by nystatin. The control strains (C.albicans, C. glabrata, C.parapsilosis, C. krusei and C. tropicalis) confirmed the values which were found for the wild strains. The spectrophotometric measuring of the turbidimetry revealed slightly lower MIC values for Candida species. Spectrophotometric measurment of Geotrichum candidum and Trichosporon mucoides was unsuccessful or not possible; however, visual reading of the results was carried out effectively. Nystatin showed very good in vitro activity against these non-Candida yeast species. In conclusion, very good in vitro activity of nystatin against all tested yeast strains could be detected. The in vitro efficacy was independent of the origin of the strains, as both the wild strains isolated from patients in this study, and the control strains originating from strain collections, were inhibited.
\end{abstract}

\section{Introduction}

The common use of azole antifungal agents, in particular oral fluconazole, but also topical azoles, for the treatment of cutaneous and oral candidiasis, and possibly due to the use of azole fungicides in agricultural crop protection, has led to the emergence of azole and echinocandine resistance of clinical isolates of Candida (C.) albicans and other Candida species [1]. An alternative therapeutic approach is the use of topical polyene antifungals such as amphotericin B or nystatin. Only limited current data exists regarding Candida species which are resistant to polyene antifungals. Recently, a total of 201 clinical C. albicans isolates from Turkey investigated by Etest were found to be susceptible to amphotericin B [2]. A similar situation can be found for nystatin. However, in vitro susceptibility testing studies have shown a low percentage of Candida species isolated from HIV positive patients to be resistant to nystatin [3].

In this study, a total of 14 currently isolated yeast strains from dermatomycosis patients, and seven reference strains (controls), including isolates from the DSMZ strain collection (German Collection of Microorganisms and Cell Cultures, Braunschweig, Germany) and inter-laboratory ring tests of INSTAND e.V. (the German Society for Promoting Quality Assurance in Medical Laboratories, Düsseldorf, Germany), were tested for their in vitro susceptibility to the polyene antifungal agent nystatin. A broth microdilution assay which corresponded to the method of the European Committee on Antimicrobial Susceptibility Testing (EUCAST), and allowed for determination of the minimal inhibitory concentration (MIC) of nystatin, was used for this purpose.

\section{Materials and methods}

\section{Active substance}

Nystatin: Pure nystatin from Dr. R. Pfleger GmbH, Bamberg, Germany was used in this study. Each ampoule contained: nystatin, lyophilized, approximately 195,000 International Units (IU); stored at refrigerator temperature of $4^{\circ} \mathrm{C}$. The active substance content corresponded to 5916 IU nystatin per milligram.

\section{Test strains}

Sensitivity testing was performed using test strains from routine

Correspondence to: Dr. Pietro Nenoff, Dermatology, Laboratory Medicine, Allergy \& Andrology Specialist; Main Focus: Tropical and Travel Dermatology (DDA), Mölbiser Hauptstraße 8, 04571 Rötha/OT Mölbis, Germany; Tel: +4934347-50 323; Fax +49-34347-50 123; E-mail: pietro.nenoff@gmx.de

Received: October 31, 2016; Accepted: November 17, 2016; Published: November 22, 2016 
Nenoff P (2016) In vitro susceptibility testing of yeasts to nystatin - low minimum inhibitory concentrations suggest no indication of in vitro resistance of Candida albicans, Candida species or non-Candida yeast species to nystatin

diagnostic testing at the Laboratory for Medical Microbiology in Mölbis (Table 1). Five reference strains (isolates from the DSMZ, Braunschweig, Germany) and two inter-laboratory ring test strains (INSTAND e. V., Düsseldorf, Germany) were used as controls (Table 1). The following 14 wild strains were investigated: C. albicans (4 strains), C. glabrata (2 strains), C. krusei (2 strains), C. parapsilosis (2 strains), C. kefyr (1 strain), Geotrichum candidum (1 strain), and Trichosporon mucoides (2 strains, Table 2).

\section{Culture media}

In accordance with EUCAST specifications [EUCAST Definitive Document EDef 7.2 Revision], fully synthetic Roswell Park Memorial Institute (RPMI) 1640 medium with L-glutamine (Sigma-Aldrich Chemie GmbH, Schnelldorf, product R8758-1L, Germany), supplemented with glucose to a final concentration of $20 \mathrm{~g} / \mathrm{l}(2 \%)$, was used for susceptibility testing [4]. 3-Morpholinopropanesulfonic acid (MOPS, Sigma-Aldrich Chemie GmbH, Schnelldorf, product no. M3183-100G, Germany), adjusted to a final concentration of $0.165 \mathrm{~mol} / \mathrm{l}$ and a $\mathrm{pH}$ of 7.0, was used as the buffer for the RPMI 1640 medium.

\section{Procedure for testing the antifungal sensitivities of Candida and other yeast species to nystatin by broth microdilution assay according to EUCAST}

The broth microdilution assay according to EUCAST [Method for the determination of broth dilution minimum inhibitory concentrations of antifungal agents for yeasts, EUCAST DEFINITIVE DOCUMENT EDef 7.2 Revision] was used to assess the antifungal activity of nystatin against the specified yeasts in vitro. This method

Table 1. Control strains.

5 isolates from the DSMZ (DSM) strain collection (Braunschweig, Germany) Candida albicans

https://www.dsmz.de/catalogues/details/culture/DSM-28719.html

Candida tropicalis

https://www.dsmz.de/catalogues/details/culture/DSM-28720.html

Candida glabrata

https://www.dsmz.de/catalogues/details/culture/DSM-28718.html

Candida krusei

https://www.dsmz.de/catalogues/details/culture/DSM-28721.html

Candida parapsilosis

https://www.dsmz.de/catalogues/details/culture/DSM-28722.html

2 strains from INSTAND e.V. Mycology Ring Trials (Düsseldorf, Germany)

Candida tropicalis INSTAND e.V. Mycology Ring Trial 09/2008, Strain 3

Candida lusitaniae INSTAND e.V. Mycology Ring Trial 1/2005, Strain 4

Table 2. Clinical isolates and sources of the yeast strains investigated in this in vitro study.

\begin{tabular}{|l|l|}
\hline Yeast & Origin \\
\hline Candida albicans $115370 / 2015$ & Oral mucosa \\
\hline Candida albicans $803972 / 2015$ & Stool / intestine \\
\hline Candida albicans $115323 / 2015$ & Urethral swab \\
\hline Candida albicans $115369 / 2015$ & Skin at corner of mouth \\
\hline Candida glabrata $703950 / 2015$ & Urine / genital area \\
\hline Candida parapsilosis $113753 / 2014$ & Throat swab \\
\hline Candida parapsilosis $216209 / 2015$ & Fungal nail clippings, first digit (both sides) \\
\hline Candida krusei $703658 / 2015$ & Urine \\
\hline Candida krusei $113204 / 2015$ & Vaginal swab \\
\hline Candida kefyr $803965 / 2015$ & Stool \\
\hline Geotrichum candidum $803545 / 2015$ & Stool \\
\hline Trichosporon mucoides $215610 / 2015$ & Toe nail \\
\hline Trichosporon mucoides $215470 / 2015$ & Toe nail \\
\hline
\end{tabular}

Table 3. Method of serial dilution of nystatin and final concentration of the antifungal agent in the serial dilution test.

\begin{tabular}{|c|c|c|c|c|}
\hline \multirow{2}{*}{ No. } & \multicolumn{2}{|c|}{$\begin{array}{c}\text { Nystatin } \\
\text { Working solution }\end{array}$} & \multicolumn{2}{c|}{$\begin{array}{c}\text { Nystatin } \\
\text { Final concentration }\end{array}$} \\
\hline & $\mathrm{IU} / \mathrm{ml}$ & $\mu \mathrm{g} / \mathrm{mL}$ & $\mathrm{IU} / \mathrm{ml}$ per well & $\mu \mathrm{g} / \mathrm{mL}$ per well \\
\hline I & 11832 & 2000 & 59.16 & 10 \\
\hline II & 5916 & 1000 & 29.58 & 5.0 \\
\hline III & 2958 & 500 & 14.79 & 2.5 \\
\hline IV & 1479 & 250 & 7.4 & 1.25 \\
\hline V & 740 & 125 & 3.7 & 0.625 \\
\hline VI & 370 & 62.5 & 1.85 & 0.312 \\
\hline VII & 185 & 31.25 & 0.92 & 0.156 \\
\hline VIII & 92 & 15.55 & 0.46 & 0.078 \\
\hline IX & 46 & 7.77 & 0.23 & 0.039 \\
\hline X & 23 & 3.88 & 0.115 & 0.0195 \\
\hline XI & \multicolumn{2}{|c|}{ Growth control } & & \\
\hline XII & \multicolumn{2}{|c|}{ Sterility control } & & \\
\hline
\end{tabular}

allows for determination of the minimum inhibitory concentration for each strain in IU/mL (and $\mu \mathrm{g} / \mathrm{mL}$ ). RPMI 1640 medium was used in sensitivity testing.

\section{Serial dilution of nystatin}

Nystatin was serially diluted with phosphate buffer $\mathrm{pH} 6.0$ to 10 different concentrations (Table 3). Nystatin stock solution was prepared by mixing the pure substance with the solvent $\mathrm{N}$, N-dimethylformamide (DMF, CNR C95257) to yield a solution with a nystatin concentration of $11832 \mathrm{IU} / \mathrm{mL}(2000 \mu \mathrm{g} / \mathrm{mL})$. The stock solution with an antimicrobial concentration of $11832 \mathrm{U} / \mathrm{mL}$ was then serially diluted with phosphate buffer pH 6.0 (CNR C99070) at a ratio of 1:2 to yield a total of 10 different test concentrations. The serial 1:2 dilution pattern yielded a geometric dilution series of working solutions with nystatin concentrations ranging from $11832 \mathrm{IU} / \mathrm{ml}(2000 \mu \mathrm{g} / \mathrm{mL}$, highest concentration) to $23 \mathrm{IU} / \mathrm{ml}(3,88 \mu \mathrm{g} / \mathrm{mL}$, lowest concentration).

\section{Preparation of microdilution plates}

Testing was performed using sterile, flat-bottom 96-good microdilution plates with a total volume of approximately $300 \mu \mathrm{l}$. $100 \mu \mathrm{l}$ of each respective nystatin working solution was diluted with $9.9 \mathrm{ml}$ [2X RPMI / 2\% glucose], equivalent to a ratio of 1:100. Next, $100 \mu \mathrm{l}$ of the respective nystatin solution was pipetted into the respective wells numbered 1 to 10 . Thus, each well contained $100 \mu \mathrm{l}$ of the respective nystatin working solution and $2 \mathrm{X}$ concentrated RPMI 1640 / $2 \%$ glucose medium with $1 \%$ solvent. By subsequent 1:2 dilution with inoculum, the final concentration of nystatin in the test wells was adjusted to $59.16 \mathrm{IU} / \mathrm{ml}(10 \mu \mathrm{g} / \mathrm{mL})$ to $0.115 \mathrm{IU} / \mathrm{ml}(0.0195 \mu \mathrm{g} /$ $\mathrm{mL}$ ), respectively (Table 3 ). Column 11, the growth control, contained antifungal-free [2X RPMI 1640 / 2\% glucose] medium. Column 12, the sterility control, contained antifungal-free RPMI medium (with no nystatin); $100 \mu \mathrm{l}$ distilled water was added instead of inoculum.

\section{Inoculum}

The inoculum was prepared using 18 - to 48 -hour-old yeast cultures grown on Sabouraud's 4\% dextrose agar (under aerobic conditions at $35^{\circ} \mathrm{C}$ ). The yeast suspensions were prepared using distilled water. The densities of the test cell suspensions ranged from 0.5 to $2.5 \times 10^{5}$ colony-forming units $(\mathrm{CFU})$ per milliliter $\left[\mathrm{CFU} \times \mathrm{ml}^{-1}\right]$. This was accomplished by comparison with a McFarland standard (bioMérieux SA, Marcy l'Etoile, France): McFarland standard no. $0.5=1-5 \times 10^{6}$ $\mathrm{CFU} / \mathrm{mL}$. A working suspension with $1-5 \times 10^{5} \mathrm{CFU} / \mathrm{mL}$ was achieved by subsequent preparation of a 1:10 dilution (with distilled water). 
Nenoff P (2016) In vitro susceptibility testing of yeasts to nystatin - low minimum inhibitory concentrations suggest no indication of in vitro resistance of Candida albicans, Candida species or non-Candida yeast species to nystatin

In each case, the yeast cell density was checked and confirmed by transferring cells to Sabouraud's dextrose agar and subsequently counting the colonies (after 24 or 48 hours of incubation).

A MultiPipette was used to dispense the yeast suspensions onto the plates $(100 \mu \mathrm{l}$ inoculum per well, columns 1 to 11$)$. Subsequent 1:2 dilution with nystatin/[RPMI 1640 / 2\% glucose] working solution was performed to yield the aforementioned test yeast cell suspension concentrations ranging from 0.5 to $2.5 \times 10^{5} \mathrm{CFU} / \mathrm{ml}$ in the microplates.

Incubation was performed under aerobic conditions at $36{ }^{\circ} \mathrm{C}$. Visual readings were obtained after 24 and 48 hours of incubation. Turbidity i.e. growth inhibition on the microplates was also determined spectrophotometrically at $450 \mathrm{~nm}$ after 24 and 48 hours of incubation. The absorbance measured with the blank sample (background absorbance) was deducted from the absorbance values obtained with the test samples. The MIC was defined as the lowest concentration of the active substance that inhibited growth of the microorganisms.

Growth controls in antifungal-free culture medium (RPMI 1640, column 11) and sterility controls containing no inoculum (column 12) were run with each MIC determination.

The $\mathrm{MIC}_{50}$, which represents the MIC that inhibits $50 \%$ of the isolates, and the $\mathrm{MIC}_{90}$ which represents the MIC which inhibits $90 \%$ of the isolates of the species tested, was calculated.

\section{Results}

In each case, the MIC values were read visually and spectrophotometrically (at $450 \mathrm{~nm}$ ), after 24 and, and 48 hours of incubation at $36^{\circ} \mathrm{C}$. All yeast strains were tested in duplicate.

\section{Visual reading}

After 24 hours of incubation, the growth of the vast majority of studied yeast strains allowed MIC reading which could be considered as conclusive. All Candida species could be fully evaluated after 24 hours of incubation (Tables $4 \mathrm{a}, 4 \mathrm{~b}$ and $4 \mathrm{c}$ ). The Geotrichum candidum

Table 4a. Minimum inhibitory concentrations (MIC) of nystatin against various yeast strains (Candida albicans, Candida glabrata and Candida parapsilosis) as determined by broth microdilution assay according to EUCAST. MIC values of strains (double determination) were read after 24 and 48 hours of incubation at $36^{\circ} \mathrm{C}$. Visual reading.

\begin{tabular}{|c|c|c|c|c|}
\hline \multirow[t]{2}{*}{ Yeast strain } & \multicolumn{2}{|c|}{ Nystatin MIC in IU/ml } & \multicolumn{2}{|c|}{ Nystatin MIC in $\mu \mathrm{g} / \mathrm{ml}$} \\
\hline & $\begin{array}{l}\text { 24-hour } \\
\text { reading }\end{array}$ & 48-hour reading & 24-hour reading & 48-hour reading \\
\hline \multirow{2}{*}{$\begin{array}{l}\text { Candida albicans } \\
115370 / 2015\end{array}$} & 3.7 & 7.4 & 0.625 & 1.25 \\
\hline & 3.7 & 7.4 & 0.625 & 1.25 \\
\hline \multirow{2}{*}{$\begin{array}{l}\text { Candida albicans } \\
803972 / 2015\end{array}$} & 7.4 & 7.4 & 1.25 & 1.25 \\
\hline & 7.4 & 7.4 & 1.25 & 1.25 \\
\hline \multirow{2}{*}{$\begin{array}{l}\text { Candida albicans } \\
115323 / 2015\end{array}$} & 7.4 & 7.4 & 1.25 & 1.25 \\
\hline & 7.4 & 7.4 & 1.25 & 1.25 \\
\hline \multirow{2}{*}{$\begin{array}{l}\text { Candida albicans } \\
115369 / 2015\end{array}$} & 7.4 & 7.4 & 1.25 & 1.25 \\
\hline & 7.4 & 7.4 & 1.25 & 1.25 \\
\hline \multirow{2}{*}{$\begin{array}{l}\text { Candida glabrata } \\
703950 / 2015\end{array}$} & 3.7 & 7.4 & 0.625 & 1.25 \\
\hline & 3.7 & 7.4 & 0.625 & 1.25 \\
\hline \multirow{2}{*}{$\begin{array}{l}\text { Candida glabrata Routine } \\
\text { strain, Mycology Course } \\
\text { Cologne } 2015\end{array}$} & 3.7 & 7.4 & 0.625 & 1.25 \\
\hline & 7.4 & 7.4 & 1.25 & 1.25 \\
\hline \multirow{2}{*}{$\begin{array}{l}\text { Candida parapsilosis } \\
113753 / 2014\end{array}$} & 7.4 & 14.79 & 1.25 & 2.5 \\
\hline & 7.4 & 14.79 & 1.25 & 2.5 \\
\hline \multirow{2}{*}{$\begin{array}{l}\text { Candida parapsilosis } \\
216209 / 2015\end{array}$} & 7.4 & 14.79 & 1.25 & 2.5 \\
\hline & 7.4 & 7.4 & 1.25 & 1.25 \\
\hline $\mathrm{MIC}_{50}$ & 7.4 & 7.4 & 1.25 & 1.25 \\
\hline $\mathrm{MIC}_{90}$ & 7.4 & 14.79 & 1.25 & 2.5 \\
\hline
\end{tabular}

Table 4b. Minimum inhibitory concentrations (MIC) of nystatin against various yeast strains (Candida krusei, Candida tropicalis, Candida lusitaniae, Candida kefyr, Geotrichum candidum and Trichosporon mucoides) as determined by broth microdilution assay according to EUCAST. MIC readings (double determination) were taken after 24 and 48 hours of incubation at $36^{\circ} \mathrm{C}$. Visual reading

\begin{tabular}{|c|c|c|c|c|}
\hline \multirow[t]{2}{*}{ Yeast strain } & \multicolumn{2}{|c|}{ Nystatin $\mathrm{MIC}$ in IU/ml } & \multicolumn{2}{|c|}{ Nystatin MIC in $\mu \mathrm{g} / \mathrm{ml}$} \\
\hline & $\begin{array}{l}\text { 24-hour } \\
\text { reading }\end{array}$ & 24-hour reading & 24-hour reading & 48-hour reading \\
\hline \multirow{2}{*}{$\begin{array}{l}\text { Candida krusei } \\
703658 / 2015\end{array}$} & 7.4 & 7.4 & 1.25 & 1.25 \\
\hline & 7.4 & 7.4 & 1.25 & 1.25 \\
\hline \multirow{2}{*}{$\begin{array}{l}\text { Candida krusei } \\
113204 / 2015\end{array}$} & 7.4 & 14.79 & 1.25 & 2.5 \\
\hline & 7.4 & 14.79 & 1.25 & 2.5 \\
\hline \multirow{2}{*}{$\begin{array}{l}\text { Candida tropicalis } \\
\text { Ring Trial 09/2008 } \\
\text { Strain } 3\end{array}$} & 3.7 & 7.4 & 0.625 & 1.25 \\
\hline & 3.7 & 7.4 & 0.625 & 1.25 \\
\hline \multirow{2}{*}{$\begin{array}{l}\text { Candida lusitaniae } \\
\text { Ring Trial 1/2005 } \\
\text { Strain } 4\end{array}$} & 7.4 & 7.4 & 1.25 & 1.25 \\
\hline & 3.7 & 7.4 & 0.625 & 1.25 \\
\hline \multirow{2}{*}{$\begin{array}{l}\text { Candida kefyr } \\
803965 / 2015\end{array}$} & 7.4 & 7.4 & 1.25 & 1.25 \\
\hline & 7.4 & 7.4 & 1.25 & 1.25 \\
\hline \multirow{2}{*}{$\begin{array}{l}\text { Geotrichum candidum } \\
\text { 803545/2015 }\end{array}$} & Not evaluable & Not evaluable & Not evaluable & Not evaluable \\
\hline & Not evaluable & 7.4 & Not evaluable & 1.25 \\
\hline \multirow{2}{*}{$\begin{array}{l}\text { Trichosporon } \\
\text { mucoides } \\
215610 / 2015\end{array}$} & Not evaluable & 7.4 & Not evaluable & 1.25 \\
\hline & Not evaluable & 7.4 & Not evaluable & 1.25 \\
\hline \multirow{2}{*}{$\begin{array}{l}\text { Trichosporon } \\
\text { mucoides } \\
215470 / 2015\end{array}$} & Not evaluable & 7.4 & Not evaluable & 1.25 \\
\hline & Not evaluable & 7.4 & Not evaluable & 1.25 \\
\hline $\mathrm{MIC}_{50}$ & 7.4 & 7.4 & 1.25 & 1.25 \\
\hline $\mathrm{MIC}_{90}$ & 7.4 & 14.79 & 1.25 & 2.5 \\
\hline
\end{tabular}

Table 4c. Minimum inhibitory concentrations (MIC) of nystatin against various control strains (reference strains/collection strains of Candida albicans, Candida glabrata, Candida parapsilosis, Candida krusei and Candida tropicalis) as determined by broth microdilution assay according to EUCAST. MIC readings (double determination) were taken after 24 and 48 hours of incubation at $36^{\circ} \mathrm{C}$. Visual reading

\begin{tabular}{|l|c|c|c|c|}
\hline \multirow{2}{*}{ Yeast strain } & \multicolumn{2}{|c|}{ Nystatin MIC in IU/ml } & \multicolumn{2}{c|}{ Nystatin MIC in $\boldsymbol{\mu g} / \mathbf{m l}$} \\
\hline & $\begin{array}{c}24-\text {-hour } \\
\text { reading }\end{array}$ & 48-hour reading & 24-hour reading & 48-hour reading \\
\hline Candida albicans & 7.4 & 7.4 & 1.25 & 1.25 \\
\hline DSM 28719 & 7.4 & 7.4 & 1.25 & 1.25 \\
\hline Candida glabrata & 7.4 & 7.4 & 1.25 & 1.25 \\
\hline DSM 28718 & 7.4 & 7.4 & 1.25 & 1.25 \\
\hline Candida parapsilosis & 7.4 & 14.79 & 1.25 & 2.5 \\
\hline DSM 28722 & 7.4 & 7.4 & 1.25 & 1.25 \\
\hline $\begin{array}{l}\text { Candida krusei } \\
\text { (Pichia kudriavzevii) }\end{array}$ & 7.4 & 7.4 & 1.25 & 1.25 \\
\hline DSM 28721 & 7.4 & 7.4 & 1.25 & 1.25 \\
\hline $\begin{array}{l}\text { Candida tropicalis } \\
\text { DSM 28720 }\end{array}$ & 3.7 & 7.4 & 0.625 & 1.25 \\
\hline MIC $_{50}$ & 3.7 & 7.4 & 0.625 & 1.25 \\
\hline MIC $_{90}$ & 7.4 & 7.4 & 1.25 & 1.25 \\
\hline
\end{tabular}

strain and the two Trichosporon mucoides strains grew slower per se and thus could not be evaluated until the second day (Table 4b).

The MIC values of nystatin were in the range of 3.7 to $7.4 \mathrm{IU} / \mathrm{mL}$ (0.625 to $1.25 \mu \mathrm{g} / \mathrm{mL}$ ) for all Candida species (Tables $4 \mathrm{a}, 4 \mathrm{~b}$ and $4 \mathrm{c}$ ). Specifically, the MICs for one C. albicans strain, the two C. glabrata strains and C. tropicalis were in the low range of $3.7 \mathrm{IU} / \mathrm{mL}(0.625$ $\mu \mathrm{g} / \mathrm{mL})$. The two non-Candida species, Geotrichum candidum and Trichosporon mucoides, were also inhibited well by nystatin; the MIC values for these yeasts remained constant at $7.4 \mathrm{IU} / \mathrm{mL}(1.25 \mu \mathrm{g} /$ $\mathrm{mL}$, Table $4 \mathrm{~b})$. The five reference strains from the DSMZ collection (Braunschweig, Germany) (C. albicans, C. glabrata, C. parapsilosis, C. krusei and C. tropicalis) confirmed the MIC values obtained for 
Nenoff P (2016) In vitro susceptibility testing of yeasts to nystatin - low minimum inhibitory concentrations suggest no indication of in vitro resistance of Candida albicans, Candida species or non-Candida yeast species to nystatin

the wild strains. The minimum inhibitory concentrations for these DSM Candida strains also ranged from $3.7 \mathrm{IU} / \mathrm{mL}(0.625 \mu \mathrm{g} / \mathrm{mL}, C$. tropicalis) to $7.4 \mathrm{IU} / \mathrm{mL}(1.25 \mu \mathrm{g} / \mathrm{mL}$, Table $4 \mathrm{c})$.

\section{Spectrophotometric measurement and determination of MIC}

The minimum inhibitory concentrations obtained by spectrophotometric absorbance measurement and optical density determination based on turbidity due to growth of the investigated yeast strains are presented in Tables 5 a-c. Compared to the visual readings, the spectrophotometrically determined MIC values for the clinical isolates of C. albicans and C. glabrata were slightly lower: 3.7 $\mathrm{IU} / \mathrm{mL}(0.625 \mu \mathrm{g} / \mathrm{mL})$ at 24 hours. Spectrophotometric readings at 48 hours were also lower: in contrast to the visual readings, only a few strains had a photometric MIC value of $7.4 \mathrm{IU} / \mathrm{mL}(1.25 \mu \mathrm{g} / \mathrm{mL}$, Tables $5 \mathrm{a}, 5 \mathrm{~b}$ and $5 \mathrm{c})$.

C. parapsilosis: After 24 hours of incubation, spectrophotometric determination of the MIC for this slowly growing yeast was not possible, but visual reading was feasible (Table $4 a$, Table 5a). After 48 hours, the MIC values determined by spectrophotometry were in the range of $7.4 \mathrm{IU} / \mathrm{mL}(1.25 \mu \mathrm{g} / \mathrm{mL})$, which is slightly lower than the visual readings (Table $5 \mathrm{a}$ ).

C. krusei, C. lusitaniae, C. tropicalis and C. kefyr were well measurable. The spectrophotometrically and visually determined minimum inhibitory concentrations for these yeasts were comparable, but those determined by spectrophotometry tended to be slightly lower (Table 5b).

Geotrichum candidum (known as the "cheese mold") and Trichosporon mucoides are slow-growing yeasts that do not tend to develop homogeneous growth. Geotrichum candidum, in particular, tends to develop relatively large single colonies at the bottom of

Table 5a. Minimum inhibitory concentrations (MIC) of nystatin against various yeast strains (Candida albicans, Candida glabrata and Candida parapsilosis) as determined by broth microdilution assay according to EUCAST. MIC readings (double determination) were taken after 24 and 48 hours of incubation at $36^{\circ} \mathrm{C}$. Spectrophotometric readings were taken at $450 \mathrm{~nm}$. The cut-off was defined as an optical density (OD) value of 0.300 . All OD values $>0.300$ were interpreted as positive for yeast growth.

\begin{tabular}{|c|c|c|c|c|}
\hline \multirow[t]{2}{*}{ Yeast strain } & \multicolumn{2}{|c|}{ Nystatin MIC in IU/ml } & \multicolumn{2}{|c|}{ Nystatin MIC in $\mu \mathrm{g} / \mathrm{ml}$} \\
\hline & $\begin{array}{l}\text { Measurement: } \\
24 \text { hours }\end{array}$ & $\begin{array}{l}\text { Measurement: } \\
48 \text { hours }\end{array}$ & $\begin{array}{l}\text { Measurement: } \\
24 \text { hours }\end{array}$ & $\begin{array}{l}\text { Measurement: } \\
48 \text { hours }\end{array}$ \\
\hline \multirow{2}{*}{$\begin{array}{l}\text { Candida albicans } \\
115370 / 2015\end{array}$} & 3.7 & 3.7 & 0.625 & 0.625 \\
\hline & 3.7 & 3.7 & 0.625 & 0.625 \\
\hline \multirow{2}{*}{$\begin{array}{l}\text { Candida albicans } \\
803972 / 2015\end{array}$} & 3.7 & 7.4 & 0.625 & 1.25 \\
\hline & 3.7 & 7.4 & 0.625 & 1.25 \\
\hline \multirow{2}{*}{$\begin{array}{l}\text { Candida albicans } \\
115323 / 2015\end{array}$} & 3.7 & 7.4 & 0.625 & 1.25 \\
\hline & 3.7 & 3.7 & 0.625 & 0.625 \\
\hline \multirow{2}{*}{$\begin{array}{l}\text { Candida albicans } \\
115369 / 2015\end{array}$} & 3.7 & 7.4 & 0.625 & 1.25 \\
\hline & 3.7 & 7.4 & 0.625 & 1.25 \\
\hline \multirow{2}{*}{$\begin{array}{l}\text { Candida glabrata } \\
703950 / 2015\end{array}$} & 3.7 & 7.4 & 0.625 & 1.25 \\
\hline & 3.7 & 7.4 & 0.625 & 1.25 \\
\hline \multirow{2}{*}{$\begin{array}{l}\text { Candida glabrata } \\
\text { Routine strain, } \\
\text { Mycology Course } \\
\text { Cologne } 2015\end{array}$} & 3.7 & 3.7 & 0.625 & 0.625 \\
\hline & 3.7 & 3.7 & 0.625 & 0.625 \\
\hline \multirow{2}{*}{$\begin{array}{l}\text { Candida parapsilosis } \\
113753 / 2014\end{array}$} & Not evaluable & 7.4 & Not evaluable & 1.25 \\
\hline & Not evaluable & 7.4 & Not evaluable & 1.25 \\
\hline \multirow{2}{*}{$\begin{array}{l}\text { Candida parapsilosis } \\
216209 / 2015\end{array}$} & Not evaluable & 7.4 & Not evaluable & 1.25 \\
\hline & Not evaluable & 3.7 & Not evaluable & 0.625 \\
\hline $\mathrm{MIC}_{50}$ & 3.7 & 7.4 & 0.625 & 1.25 \\
\hline $\mathrm{MIC}_{90}$ & 3.7 & 7.4 & 0.625 & 1.25 \\
\hline
\end{tabular}

microplate wells. Consequently, photometric measurement is problematic and inferior to visual reading in these cases. When determined by spectrophotometry, the measured optical density values does not apply to the visual readout method, with which (as described above) a good inhibitory effect of nystatin against the two arthrosporeforming yeast species was observed.

In the spectrophotometric evaluation, the in vitro susceptibility of the reference strains from the DSMZ Braunschweig corresponded to that of the wild strains. C.parapsilosis and C. krusei: Spectrophotometric determination of the MICs for these strains was only possible after 48 hours of incubation (Table $5 \mathrm{c}$ ). The spectrophotometrically determined MIC values for the other yeasts were generally comparable and, in isolated cases, slightly lower than the corresponding visual readings.

\section{Discussion}

Nystatin is a polyene antifungal agent which therefore belongs to the same group of antifungal substances as amphotericin B and natamycin. Structurally, nystatin belongs to the family of polyene macrolide antibiotics and was first successfully isolated in 1950 from the bacterium Streptomyces noursei. The drug has subsequently been available as a "classical" topical antifungal agent which is used to treat fungal diseases of the skin and mucous membranes. Nystatin is a yellowish powder which is practically insoluble in water but soluble in propylene glycol and dimethylformamide [5]. Nystatin undergoes slow degradation in aqueous suspensions. The drug is sensitive to light, heat, oxygen and $\mathrm{pH}$ shifts below $\mathrm{pH} 3$ and above $\mathrm{pH} 9$.

The mechanism of action of nystatin is based on binding of the polyene to sterols in the yeast plasma membrane resulting in a change in their permeability. Consequently, the fungal cells lose potassium, and cellular respiration. Nystatin has a fungistatic effect but can also show fungicidal activity at high concentrations.

The primary activity of nystatin both in vitro as well as in vivo in patients involves mainly yeasts. C. albicans and other Candida species are significantly inhibited by nystatin. Nystatin is also known to have an inhibitory effect on some molds.

Nystatin is used for the topical treatment of cutaneous and mucosal fungal infections caused by C. albicans and other yeast species. Examples of these infections include cutaneous candidiasis involving intertriginous areas (e.g. groin or between fingers) and the free skin. Candida infections of the orointestinal tract, as well as infections of the mucous membranes of the genital tract caused by C. albicans and other Candida species, can be effectively treated using nystatin preparations [6].

Film-coated tablets for the treatment of orointestinal candidiasis contain, for example, 500,000 IU nystatin. One gram of nystatin oral gel contains, for example, 100,000 IU nystatin. Since nystatin is hardly absorbed from the gut it is not expected to cause systemic effects following oral administration.

Previously, it has been stated that no nystatin resistant yeasts exist, and in particular that there is no C. albicans which is resistant to nystatin.

In India, an in vitro study of antifungal drug susceptibility of Candida species from human immunodeficiency virus (HIV) positive and HIV negative patients with and without oropharyngeal candidiasis has recently been published [3]. Candida isolates from HIV negative are not in the evaluable range and are generally too low (Table 5b). This sugar and phosphate ions, which leads to the impairment of glycolysis 
Nenoff P (2016) In vitro susceptibility testing of yeasts to nystatin - low minimum inhibitory concentrations suggest no indication of in vitro resistance of Candida albicans, Candida species or non-Candida yeast species to nystatin

Table 5b. Minimum inhibitory concentrations (MIC) of nystatin against various yeast strains (Candida krusei, Candida tropicalis, Candida lusitaniae, Candida kefyr, Geotrichum candidum and Trichosporon mucoides) as determined by broth microdilution assay according to EUCAST. MIC values (double determination) were read after 24 and 48 hours of incubation at $36{ }^{\circ} \mathrm{C}$. Spectrophotometric readings were taken at $450 \mathrm{~nm}$. The cut-off was defined as an optical density (OD) value of 0.300 . All OD values $>0.300$ were interpreted as positive for yeast growth.

\begin{tabular}{|c|c|c|c|c|}
\hline \multirow[t]{2}{*}{ Yeast strain } & \multicolumn{2}{|c|}{ Nystatin MIC in IU/ml } & \multicolumn{2}{|c|}{ Nystatin MIC in $\mu \mathrm{g} / \mathrm{ml}$} \\
\hline & Measurement: 24 hours & Measurement: 48 hours & Measurement: 24 hours & Measurement: 48 hours \\
\hline \multirow[t]{2}{*}{ Candida krusei 703658/2015 } & 7.4 & 7.4 & 1.25 & 1.25 \\
\hline & 7.4 & 7.4 & 1.25 & 1.25 \\
\hline \multirow[t]{2}{*}{ Candida krusei 113204/2015 } & 7.4 & 7.4 & 1.25 & 1.25 \\
\hline & 7.4 & 7.4 & 1.25 & 1.25 \\
\hline \multirow[t]{2}{*}{ Candida tropicalis Ring Trial 09/2008 Strain 3} & 3.7 & 3.7 & 0.625 & 0.625 \\
\hline & 3.7 & 3.7 & 0.625 & 0.625 \\
\hline \multirow[t]{2}{*}{ Candida lusitaniae Ring Trial 1/2005 Strain 4} & 7.4 & 7.4 & 1.25 & 1.25 \\
\hline & 3.7 & 7.4 & 0.625 & 1.25 \\
\hline \multirow[t]{2}{*}{ Candida kefyr $803965 / 2015$} & 3.7 & 1,85 & 0.625 & 0.3125 \\
\hline & 3.7 & 3.7 & 0.625 & 0.625 \\
\hline \multirow[t]{2}{*}{ Geotrichum candidum 803545/2015 } & Not evaluable & Not evaluable / No growth & Not evaluable & Not evaluable / No growth \\
\hline & Not evaluable & $\begin{array}{l}\text { Not evaluable, but good growth } \\
\text { of large individual colonies } \\
\text { visually evaluable }\end{array}$ & Not evaluable & $\begin{array}{c}\text { Not evaluable, but good growth } \\
\text { of large individual colonies } \\
\text { visually evaluable }\end{array}$ \\
\hline \multirow[t]{2}{*}{ Trichosporon mucoides 215610/2015 } & Not evaluable & $\begin{array}{l}\text { Not evaluable, but good growth } \\
\text { of large individual colonies } \\
\text { visually evaluable }\end{array}$ & Not evaluable & $\begin{array}{l}\text { Not evaluable, but good growth } \\
\text { of large individual colonies } \\
\text { visually evaluable }\end{array}$ \\
\hline & Not evaluable & $\begin{array}{c}\text { Not evaluable, but good growth } \\
\text { of large individual colonies } \\
\text { visually evaluable }\end{array}$ & Not evaluable & $\begin{array}{c}\text { Not evaluable, but good growth } \\
\text { of large individual colonies } \\
\text { visually evaluable }\end{array}$ \\
\hline \multirow[t]{2}{*}{ Trichosporon mucoides 215470/2015 } & Not evaluable & $\begin{array}{l}\text { Not evaluable, but good growth } \\
\text { of large individual colonies } \\
\text { visually evaluable }\end{array}$ & Not evaluable & $\begin{array}{l}\text { Not evaluable, but good growth } \\
\text { of large individual colonies } \\
\text { visually evaluable }\end{array}$ \\
\hline & Not evaluable & $\begin{array}{l}\text { Not evaluable, but good growth } \\
\text { of large individual colonies } \\
\text { visually evaluable }\end{array}$ & Not evaluable & $\begin{array}{c}\text { Not evaluable, but good growth } \\
\text { of large individual colonies } \\
\text { visually evaluable }\end{array}$ \\
\hline $\mathrm{MIC}_{50}$ & 7.4 & 7.4 & 1.25 & 1.25 \\
\hline $\mathrm{MIC}_{90}$ & 7.4 & 7.4 & 1.25 & 1.25 \\
\hline
\end{tabular}

Table 5c. Minimum inhibitory concentrations (MIC) of nystatin against various control strains (reference strains/collection strains of Candida albicans, Candida glabrata, Candida parapsilosis, Candida krusei and Candida tropicalis) as determined by broth microdilution assay according to EUCAST. MIC values (double determination) were read after 24 and 48 hours of incubation at $36^{\circ} \mathrm{C}$. Spectrophotometric readings were taken at $450 \mathrm{~nm}$. The cutoff was defined as an optical density (OD) value of 0.300 . All OD values $>0.300$ were interpreted as positive for yeast growth.

\begin{tabular}{|l|c|c|c|c|}
\hline \multirow{2}{*}{ Yeast strain } & \multicolumn{2}{|c|}{ Nystatin MIC in IU/mI } & \multicolumn{2}{c|}{ Nystatin MIC in $\boldsymbol{\mu g} / \mathbf{m l}$} \\
\hline & $\begin{array}{c}\text { Measurement: } \\
24 \text { hours }\end{array}$ & $\begin{array}{c}\text { Measurement: } \\
48 \text { hours }\end{array}$ & $\begin{array}{c}\text { Measurement: } \\
24 \text { hours }\end{array}$ & $\begin{array}{c}\text { Measurement: } \\
48 \text { hours }\end{array}$ \\
\hline $\begin{array}{l}\text { Candida albicans } \\
\text { DSM 28719 }\end{array}$ & 3.7 & 7.4 & 0.625 & 1.25 \\
\hline $\begin{array}{l}\text { Candida glabrata } \\
\text { DSM 28718 }\end{array}$ & 3.7 & 7.4 & 0.625 & 1.25 \\
\hline $\begin{array}{l}\text { Candida parapsilosis } \\
\text { DSM 28722 }\end{array}$ & Not evaluable & 7.4 & Not evaluable & 1.25 \\
\hline $\begin{array}{l}\text { Candida krusei } \\
\text { (Pichia kudriavzevii) } \\
\text { DSM 28721 }\end{array}$ & Not evaluable & 7.4 & Not evaluable & 1.25 \\
\hline $\begin{array}{l}\text { Candida tropicalis } \\
\text { DSM 28720 }\end{array}$ & 1.85 & 7.4 & Not evaluable & 1.25 \\
\hline MIC $_{50}$ & 1.85 & 7.4 & Not evaluable & 1.25 \\
\hline MIC $_{50}$ & 3.7 & 7.4 & 0.3125 & 1.25 \\
\hline
\end{tabular}

patients were much more susceptible to antifungals when compared to those which were HIV positive. Candida species from HIV patients were susceptible to fluconazole in $86.1 \%$ of cases, and dose-dependent susceptible in $13.9 \%$. Resistance to fluconazole was not found. HIV negative patients showed susceptibility, dose dependent susceptibility and resistance to fluconazole in $94.1 \%, 2.9 \%$ and $2.9 \%$ of isolates. For amphotericin B in HIV positive patients, $66.7 \%$ of Candida species were susceptible, and $22.2 \%$ resistant. HIV negative individuals showed $85.3 \%$ susceptibility to amphotericin B, $5.9 \%$ dose dependent susceptibility, and $8.8 \%$ resistance. In HIV positive patients $61.1 \%$ of Candida isolates were susceptible to nystatin, $36.1 \%$ were dose dependent susceptible, and $2.8 \%$ were resistant to nystatin. Otherwise, HIV negative individuals showed nystatin susceptibility in $91.2 \%$ of isolates, dose dependent susceptibility in $8.8 \%$, and there were no nystatin resistant isolates.

It should be noted, however, that nystatin-resistant isolates of $C$. albicans have repeatedly been reported. In a recent study in Uganda, for example, nystatin resistance of $C$. albicans isolated from women with vulvovaginal candidiasis was observed in $0.61 \%$ of patients [7]. The fact that sensitivity testing in the Ugandan study was performed using a simple agar diffusion test can be regarded as a point of criticism. Conformity with recognized methods such as the EUCAST broth microdilution method was not evident.

Recently, Diaz et al. [8] determined the in vitro susceptibility of vaginal Candida isolates to fluconazole, clotrimazole and nystatin by M27-A3 microdilution method. Among the 145 isolates were $126 \mathrm{C}$. albicans, 16 C. glabrata, 2 C. parapsilosis, and one C. tropicalis. Five isolates of C. albicans and one isolate of C. tropicalis were in vitro resistant to fluconazole. Five C. glabrata and 1 C. tropicalis were in vitro resistant to clotrimazole.

The spectrum and in vitro antifungal susceptibility pattern of yeast isolates were investigated in Ethiopian HIV patients with oropharyngeal candidiasis [9]. The authors found that C. albicans was the most frequent species followed by C. glabrata, C. tropicalis, C. krusei, C. kefyr, 
Nenoff P (2016) In vitro susceptibility testing of yeasts to nystatin - low minimum inhibitory concentrations suggest no indication of in vitro resistance of Candida albicans, Candida species or non-Candida yeast species to nystatin

Cryptococcus laurentii, and Rhodotorula species. In total, $5.8 \%, 5.8 \%$, $12.3 \%, 8.4 \%$, and $0.6 \%$ of the isolates were resistant to amphotericin $\mathrm{B}$, clotrimazole, fluconazole, ketoconazole, and miconazole, respectively. $1.3 \%$ isolates were resistant to nystatin. Interestingly, the resistance was higher for amphotericin B when compared with nystatin. Not surprisingly, the azole antifungals also exhibited higher resistance levels than nystatin.

In Iran, 120 clinical isolates of C. parapsilosis from blood stream infections were tested for in vitro resistance [10]. Only three $(2.5 \%)$ C. parapsilosis strains were resistant to fluconazole, three (2.5\%) were resistant to itraconazole, and two (1.7\%) were amphotericin B resistant. In this study, nystatin was not investigated.

The present study found low MIC values for nystatin against yeasts such as C. albicans, for which the MIC of nystatin was in the range of $3.7 \mathrm{IU} / \mathrm{ml}(0.625 \mu \mathrm{g} / \mathrm{mL}, 24$ hour spectrophotometric reading). The various other yeast species were also well inhibited by nystatin in vitro at comparable minimum inhibitory concentrations, which ranged from 1.85 to $7.4 \mathrm{IU} / \mathrm{ml}(0.3125$ to $1.25 \mu \mathrm{g} / \mathrm{mL})$ and were predominantly at a focal point of $3.7 \mathrm{IU} / \mathrm{ml}(0.625 \mu \mathrm{g} / \mathrm{mL})$. Even slow-growing Candida species such as $C$. parapsilosis were also inhibited well by nystatin in vitro. C. glabrata and C. krusei, two species known to frequently develop resistance to fluconazole, and the latter which has intrinsic resistance to fluconazole, were also inhibited well by nystatin in vitro, as shown by the MIC values of 3.7 and $7.5 \mathrm{IU} / \mathrm{ml}(0.625$ to $1.25 \mu \mathrm{g} / \mathrm{mL})$, respectively.

The fact that nystatin was also shown to have very good in vitro activity against non-Candida species, such as Geotrichum candidum and Trichosporon mucoides, is worth mentioning. However, it was necessary to resort to visual read-out of growth inhibition test results as optical density measurement is error-prone due to the slow and inhomogeneous growth of these species.

\section{Conclusions}

In summary, nystatin exhibited very good in vitro activity against all of the tested yeast strains, C. albicans and non-Candida albicans species as well as Geotrichum candidum and Trichosporon mucoides, regardless of whether they were wild strains or control strains from culture collections. There was no evidence of in vitro resistance by C. albicans, other Candida species, or non-Candida yeast species to nystatin, despite the long time period in which it has been used as a topical antifungal agent.

\section{References}

1. Gonçalves SS, Souza AC, Chowdhary A, Meis JF (2016) Epidemiology and molecular mechanisms of antifungal resistance in Candida and Aspergillus. Mycoses. [Crossref]

2. Yenisehirli G, Bulut N, Yenisehirli A, Bulut Y (2015) In Vitro Susceptibilities of Candida albicans Isolates to Antifungal Agents in Tokat, Turkey. Jundishapur $J$ Microbiol 8: e28057. [Crossref]

3. Dar MS, Sreedar G, Shukla A, Gupta P, Rehan AD, et al. (2015) An in vitro study of antifungal drug susceptibility of Candida species isolated from human immunodeficiency virus seropositive and human immunodeficiency virus seronegative individuals in Lucknow population Uttar Pradesh. J Oral Maxillofac Pathol 19: 205-11.

4. Arendrup MC, Cuenca-Estrella M, Lass-Flörl C, Hope W (2012) EUCAST-AFST EUCAST technical note on the EUCAST definitive document EDef 7.2: method for the determination of broth dilution minimum inhibitory concentrations of antifungal agents for yeasts EDef 7.2 (EUCAST-AFST). Clin Microbiol Infect 18: E246-E247.

5. Seebacher C, Blaschke-Hellmessen R, (1990) Epidemiologie Diagnostik Therapie Gustav Fischer Verlag Jena 1990

6. Nenoff P, Krüger C, Paasch U, Ginter-Hanselmayer G (2015) Mycology- an update Part 3: Dermatomycoses: topical and systemic therapy. J Dtsch Dermatol Ges 13: 387-410. [Crossref]

7. Mukasa KJ, Herbert I, Daniel A, Sserunkuma KL, Joel B, et al. (2015) Antifungal Susceptibility Patterns of Vulvovaginal Candida species among Women Attending Antenatal Clinic at Mbarara Regional Referral Hospital, South Western Uganda. $\mathrm{Br}$ Microbiol Res J 5: 322-33

8. Diaz MC Camponovo R, Araya I, Cerda A, Santander MP, et al (2016) Dentification and in vitro antifungal susceptibility of vaginal Candida spp. isolates to fluconazole, clotrimazole and nystatin. Rev Esp Quimioter 29: 151-154.

9. Moges B, Bitew A, Shewaamare A (2016) Spectrum and the In Vitro Antifungal Susceptibility Pattern of Yeast Isolates in Ethiopian HIV Patients with Oropharyngeal Candidiasis. Int J Microbiol: 3037817. [Crossref]

10. Lotfali E, Kordbacheh P, Mirhendi H, Zaini F, Ghajari A, et al. (2016) Antifungal Susceptibility Analysis of Clinical Isolates of Candida parapsilosis in Iran. Iran J Public Health 45: 322-328.

Copyright: (C2016 Nenoff P. This is an open-access article distributed under the terms of the Creative Commons Attribution License, which permits unrestricted use, distribution, and reproduction in any medium, provided the original author and source are credited. 